Ergo

\title{
Lucretian Puzzles
}

\author{
MICHAEL RABENBERG \\ Center for Bioethics \\ New York University
}

\begin{abstract}
It seems that people typically prefer dying later to dying earlier. It also seems that people typically do not prefer having been created earlier to having been created later. Lucretius' Puzzle is the question whether anything typically rationally recommends having a preference for dying later to dying earlier over having a preference for having been created earlier to having been created later. In this paper, I distinguish among three ways in which Lucretius' Puzzle can be understood and say how I think they ought to be answered.
\end{abstract}

\section{Introduction}

In his philosophical poem De Rerum Natura, Lucretius writes:

Recall, then, how the past long period of everlasting time before we were born has been nothing to us. Thus nature offers to us this mirror of the future time after our eventual death. Does anything horrible appear there? Does anything seem sad? Is it not more peaceful than every sleep? ${ }^{1}$

Some philosophers have taken this passage to invite an observation and a question about death and creation. The observation: We typically have the Lucretian Asymmetry. For the moment, a rough and provisional characterization of the Lucretian Asymmetry, which will receive clarification and refinement later on,

1. De Rerum Natura III.972-77. Latin text accessed on http://www.perseus.tufts.edu. My translation. (respice item quam nil ad nos ante acta vetustas / temporis aeterni fuerit, quam nascimur ante. / hoc igitur speculum nobis natura futuri / temporis exponit post mortem denique nostram. / numquid ibi horribile apparet, num triste videtur / quicquam, non omni somno securius exstat?)

Contact: Michael Rabenberg <rabenbergm@gmail.com> 
will have to suffice: the combination of a preference that one's death be later rather than earlier and the lack of a preference that one's creation be earlier rather than later. The question: Does anything typically rationally recommend having a preference that one's death be later rather than earlier over having a preference that one's creation be earlier rather than later; and if so, what? This question is Lucretius' Puzzle. $^{2}$

A vindicatory solution to Lucretius' Puzzle would identify some difference between creation and death, or some difference between preferences concerning the past and preferences concerning the future, or some other such thing, in virtue of which having a preference that one's death be later rather than earlier has something rationally going for it that having a preference that one's creation be earlier rather than later does not. A super-vindicatory solution to Lucretius' Puzzle would do what a vindicatory solution does, but in a way that makes sense of the fact that people typically have the Lucretian Asymmetry. Not every conceivable vindicatory solution is super-vindicatory. It is conceivable that one could identify some consideration that recommends having a preference that one's death be later rather than earlier over having a preference that one's creation be earlier rather than later but that is clearly not a reason for which people typically have the Lucretian Asymmetry. But I take it that what we most want in a solution to Lucretius' Puzzle is a super-vindicatory solution. ${ }^{3}$ For I take it that what we most want in a solution to Lucretius' Puzzle is a vindication of some of our actual typical preferences concerning death and creation. But a complete vindication of those preferences would involve showing not only that there are reasons to have them that are good but also that the reasons for which we have them are good, and only a super-vindicatory solution shows this.

I said above that the way in which I have thus far characterized the Lucretian Asymmetry, namely as "the combination of a preference that one's death be later rather than earlier and the lack of a preference that one's creation be earlier rather than later," is "rough and provisional." I shall now explain why I said this. Let the term "mental asymmetry" refer to any complex composed of the possession of some mental item and the lack of some similar mental item. There are,

2. Writings at least partly on Lucretius' Puzzle include Belshaw (2000), Brueckner and Fischer (1986; 1993; 2013), Deng (2015), Feldman (1991), Finocchiaro and Sullivan (2016), Harman (2011), Johansson (2013), Kamm (1993: Chapters 2-4), Kaufman (1995; 1996; 1999; 2000), McMahan (2006), Meier (2019), Nagel (1979; 1986: 223-31), Rosenbaum (1989), Sorensen (2013), and Timmerman (2018). I am gliding over a complication: Some of these writers treat Lucretius' Puzzle as the question whether it is the case that earlier-rather-than-later death can be bad for one but later-ratherthan-earlier creation cannot be bad for one. But I think that this complication will not be important to my purposes, for I think that what one says in response to Lucretius' Puzzle construed as a question about preferences can be reformulated so as to be responsive to Lucretius' Puzzle construed as a question about personal badness, and vice-versa.

3. Here I agree with Harman (2011). 
I think, several importantly different mental asymmetries that can reasonably be characterized as "the combination of a preference that one's death be later rather than earlier and the lack of a preference that one's creation be earlier rather than later." Consequently, I think, the terms "the Lucretian Asymmetry" and "Lucretius' Puzzle" are somewhat misleading. It is better, I think, to speak of "versions of the Lucretian Asymmetry" and of "versions of Lucretius' Puzzle."

In this paper, I shall consider three versions of Lucretius' Puzzle, which I shall call the "Hope Puzzle," the "Wish Puzzle," and the "Wish Puzzle*." In Sections 2 and 3, I shall argue that the Hope Puzzle has a super-vindicatory solution. In Sections 4-6, I shall argue that the Wish Puzzle has a super-vindicatory solution. And in Sections 7-9, I shall argue that the Wish Puzzle* probably lacks a vindicatory solution (and so probably lacks a super-vindicatory solution). Finally, in Section 10, I shall argue that what I say about the three versions of Lucretius' Puzzle that I discuss could be brought to bear on any version of Lucretius' Puzzle.

\section{The Hope Puzzle}

In this section, I shall describe a mental asymmetry that can reasonably be characterized as a version of the Lucretian Asymmetry, which I shall call the "Hope Asymmetry"; and I shall articulate the version of Lucretius' Puzzle to which the Hope Asymmetry gives rise, which I shall call the "Hope Puzzle."

There are several, presumably infinitely many, conceivable ways for my life to continue from now until my death. Some of these conceivable extensions of my life into the future are, we might say, at least fairly realistic, given my evidence (e.g., some of those that are 50 years long); and some are just plain unrealistic, given my evidence (e.g., all of those that are 1,000 years long). The difference between the relevantly at-least-fairly-realistic and the relevantly just-plain-unrealistic is vague and context-sensitive, but we seem to have a pretty good intuitive grasp of the difference.

Consider the following attitude:

H+ a hope that one actually will get a longer rather than a shorter conceivable extension of one's life into the future, regardless of realisticness, if the extent to which the longer extension is good for one if it is actual is greater than the extent to which the shorter extension is good for one if it is actual

A person with $\mathrm{H}+$ prefers (say) a 1,000-year conceivable extension of his life into the future to (say) a 100-year not-as-good-for-him conceivable extension of his 
life into the future, and prefers (say) a 10o-year conceivable extension of his life into the future to (say) a 50-year not-as-good-for-him conceivable extension of his life into the future, even though only some of these might be at-least-fairly realistic, given this person's evidence. (I take no stand on whether what it is to have $\mathrm{H}+$ is to have preferences of this sort. I say only that someone with $\mathrm{H}+$ has preferences of this sort.)

In what follows, I shall refer to conceivable extensions of one's life into the future as "extensions into the future." Furthermore, I shall for the most part assume without making explicit that a longer extension into the future would be better for one than a shorter one (i.e., that, for any two extensions into the future, $\mathrm{F}+$ and F-, where F+ is longer than F-, the extent to which F+ is good for one if $\mathrm{F}+$ is actual is greater than the extent to which $\mathrm{F}$ - is good for one if $\mathrm{F}$ - is actual).

I have $\mathrm{H}+$. I hope that I shall actually go on living further and further into the future, if things will keep getting overall better and better for me, and my hope is in an obvious respect insensitive to considerations of realisticness. I am not indifferent between getting a 1,000-year extension into the future and getting a 50-year extension into the future. Certainly I do not prefer getting a 50-year extension into the future to getting a 1,000-year extension into the future. I just plain prefer getting a 1,000-year extension into the future to getting a 50-year extension into the future. And I do so despite the fact that, whereas (I know that) 1,000-year extensions into the future are extremely unrealistic, (I know that) 50-year extensions into the future are quite realistic. In this respect, my hope is - or, at any rate, the preferences of mine that are entailed by my having $\mathrm{H}+$ are-insensitive to considerations of realisticness. Furthermore, I am confident that I am not atypical in this respect. I am confident that having $\mathrm{H}+$ is typical.

Just as there are several, presumably infinitely many, conceivable ways for my life to continue into the future, there are several, presumably infinitely many, conceivable ways that my life has already gone up to now. We might call these ways "conceivable extensions of my life into the past." Some conceivable extensions of my life into the past are at least fairly realistic, given my evidence; and some are (utterly) unrealistic, given my evidence.

To illustrate: I am an animalist about human personal ontology, i.e., I believe that each human person is identical to some human organism. And there is a human organism - the one located where I am-that I believe to be identical to me. I have extremely powerful evidence that this human organism was born non-prematurely on April 13, 1988. And I am not utterly ignorant about human embryology. Thus I have, or at least I take myself to have, extremely powerful evidence that I came into existence on or at least very close to July 13, 1987, about 30 years +9 months before the time of this writing. (I finished writing this paper a few days after my 3oth birthday.) Furthermore, I very confidently believe that I came into existence at least very close to this date. 
Admittedly, I also have some evidence, which I have acquired from philosophers with views of personal ontology different from my own, that my life started a fairly small amount of time after I believe it did-perhaps when my organism became self-conscious, or when it developed a fairly large amount of brain matter, or at some other such time. However, I have virtually no evidence that my life began substantially before I believe it did, i.e., substantially before July 13, 1987. In addition, I have virtually no evidence that my life began substantially after I believe it did. Thus every conceivable extension of my life into the past with length substantially greater or substantially lesser than 30 years + 9 months is extremely unrealistic, given my evidence. So, no two at-least-fairly-realistic conceivable extensions of my life into the past differ significantly in length. And in this respect, there is nothing atypical about me. Typically, a person does not have two at-least-fairly-realistic conceivable extensions of her life into the past that differ significantly in length.

There are cases in which a person has several at-least-fairly-realistic conceivable extensions of her life into the past that differ significantly in length. For example, you wake up in the hospital with total amnesia, the nurse tells you that you are either the 40-year-old patient or the 50-year-old patient whom the doctor will see today, the nurse leaves the room to confirm which of the two patients you are-you get the idea. ${ }^{4}$ But cases of this sort are seriously atypical. Typically, we have overwhelming evidence that our lives actually stretch back such-andsuch amount of time-and pretty much no more or less than that.

Now consider the following attitude:

H- a hope that one actually has received a longer rather than a shorter conceivable extension of one's life into the past, regardless of realisticness, if the extent to which the longer extension is good for one if it is actual is greater than the extent to which the shorter extension is good for one if it is actual

A person with H- prefers (say) a 1,000-year conceivable extension of his life into the past to (say) a 100-year, not-as-good-for-him conceivable extension of his life into the past, and prefers (say) a 100-year conceivable extension of his life into the past to (say) a 50-year, not-as-good-for-him conceivable extension of his life into the past, even if-as will typically be the case-at most one of these conceivable extensions is at least fairly realistic, given the person's evidence. (I take no stand on whether or not what it is to have $\mathrm{H}$ - is to have preferences of this sort. I say only that someone with $\mathrm{H}$ - has such preferences.)

4. McMahan (2006) considers a case like this. 
In what follows, I shall refer to conceivable extensions of one's life into the past as "extensions into the past." Furthermore, I shall for the most part assume without making explicit that a longer conceivable extension of one's life into the past would be better for one than a shorter one (i.e., that, for any two extensions into the past, $\mathrm{P}+$ and $\mathrm{P}_{-}$, where $\mathrm{P}+$ is longer than $\mathrm{P}_{-}$, the extent to which $\mathrm{P}+$ is good for one if $\mathrm{P}+$ is actual is greater than the extent to which $\mathrm{P}$ - is good for one if $\mathrm{P}$ - is actual).

I do not have H-. I am confident that you do not have H-, either. Indeed, I am confident that before you read the last few paragraphs, it had never occurred to you that $\mathrm{H}$ - might be worth having; that after it occurred to you that $\mathrm{H}$ - might be worth having, you did not form H-; and that what holds for me and for you holds for nearly everyone. People typically lack H-.

The Hope Asymmetry is the combination of possession of $\mathrm{H}+$ and lack of $\mathrm{H}$-. If I am right that people typically have $\mathrm{H}+$ and typically lack $\mathrm{H}-$, then people typically have the Hope Asymmetry. Furthermore, it is reasonable to characterize H+ as "a preference that one's death be later rather than earlier" and H- as "a preference that one's creation be earlier rather than later." So, the Hope Asymmetry is a worthy candidate for being called "a version of the Lucretian Asymmetry."

Here is the version of Lucretius' Puzzle concerned with the Hope Asymmetry:

Hope Puzzle. Does anything typically rationally recommend having $\mathrm{H}+$ over having $\mathrm{H}-$ ? If so, what?

In Section 3, I shall defend a super-vindicatory solution to the Hope Puzzle.

\section{The Epistemic Solution}

One way to argue that the Hope Puzzle has a super-vindicatory solution would be to appeal to the claim that people typically are, and have good reason to be, future-biased. Roughly, to be future-biased is to be more concerned about goods and bads that one will or might receive in the future than about goods and bads that one received or might have received in the past.

Many take cases such as the following ones to support the view that people typically are, and have good reason to be, future-biased, at least about some goods and bads:

Surgery. Jones wakes up in the hospital. The nurse tells Jones that either he underwent an agonizing surgical procedure yesterday, after which he took a pill that wiped his memory of the procedure (and of all the pain), or he will undergo a painful but not agonizing surgical procedure later today, 
after which he will take a pill that will wipe his memory of the procedure (and of all the pain). The nurse leaves the room to find out whether Jones had the procedure yesterday or will have the procedure later today. While the nurse is away, Jones hopes that he had the procedure yesterday. ${ }^{5}$

Drug. Smith wakes up in the hospital. The nurse tells Smith that either he took a drug yesterday that gave him two extremely intense hours of pleasure, after which he took a pill that wiped his memory of taking the drug and of having the pleasure, or he will take a drug later today that will give him one intense but not extremely intense hour of pleasure, after which he will take a pill that will wipe his memory of taking the drug and of having the pleasure. The nurse leaves the room to find out whether Smith took the drug yesterday or will take the drug later today. While the nurse is away, Smith hopes that he will take the drug later today. ${ }^{6}$

Many who consider Surgery, upon imagining themselves to be Jones, share Jones's hope, even though Jones will have less pain overall if he has the surgery later today than if he had the surgery yesterday. Thus it appears that people prefer actually having suffered more serious bads of some kinds (e.g., painful experiences) in the past to actually suffering less serious bads of these kinds in the future, ceteris paribus. This is one way in which people can be future-biased. Similarly, many who consider Drug, upon imagining themselves to be Smith, share Smith's hope, even though Smith will have less pleasure overall if he takes the drug later today than if he took the drug yesterday. Thus it appears that people prefer actually receiving less significant goods of some kinds (e.g., pleasant experiences) in the future to actually having received more significant goods of these kinds in the past, ceteris paribus. This is another way in which people can be future-biased. Furthermore, people who consider cases such as Surgery and Drug typically take their reactions to them to be rational. People have good reason to hope that their painful experiences are in their past and that their pleasant experiences are in their future, or so many think.

The claim that people at least typically have good reason to be future-biased seems to support the conclusion that something typically rationally recommends having $\mathrm{H}+$ over having $\mathrm{H}-$. For $\mathrm{H}+$ is a hope for a longer rather than a shorter extension into the future, and $\mathrm{H}$ - is a hope for a longer rather than a shorter extension into the past. So, if people at least typically have good reason to be future-biased, then it seems plausible that the Hope Puzzle has a vindicatory

5. See Parfit (1984: 165-66).

6. Brueckner and Fischer (1986) consider a case like this in their discussion of Lucretius' Puzzle. 
solution. Furthermore, this solution would seem to be super-vindicatory; it seems plausible that at least one reason for which people typically have the Hope Asymmetry is that they are typically future-biased.

However, some philosophers have recently argued that future-bias is irrational. 7 These philosophers have not persuaded me, but I do believe that they have established that the rationality of future-bias cannot be taken for granted. Thus I believe that any successful future-bias-based vindicatory solution to the Hope Puzzle would have to involve an argument that people have good reason to be future-biased, or at least an argument against the recent arguments that futurebias is irrational. And I cannot defend an argument of either sort here.

Thus I shall set aside future-bias for the rest of this section. Instead, I shall propose a super-vindicatory solution to the Hope Puzzle that is neutral about the rationality or irrationality of future-bias.

I shall call my solution to the Hope Puzzle the epistemic solution. The epistemic solution has at its core the following principle:

(Seriously Mistaken) Typically, one has good reason to hope that one is not seriously mistaken about one's own life.

(Seriously Mistaken) seems to me to have great intuitive force. Most of us are disturbed by the thought that we might be brains in vats upon entertaining this thought. Why? Presumably at least a big part of what makes this thought disturbing is the fact that the thought that one is seriously mistaken about one's own life is disturbing. You take yourself to be a human being, with this spouse and those children and that career and those parents and so on, but now you are entertaining the possibility that you are wrong about all of that. (Seriously Mistaken) implies that we typically have good reason to hope that we are not in serious error about who we are, about how our lives have gone, and so on.

There are many ways in which one can be seriously mistaken about one's own life. Being the subject of a nearly total delusion of the sort of which one is a subject if one is a brain in a vat is one such way, but there are others. If there is a significant segment of your life (a decade-long segment, say) of which you are entirely ignorant, and such that you have organized your life to a significant extent around the assumption that there is no such segment, then you almost certainly count as seriously mistaken about your own life. The thought that one's life might contain such a segment might be less disturbing than the thought that one might be the subject of a nearly total, brain-in-a-vat-style delusion. But it is surely disturbing.

7. See Brink (2011), Dougherty (2011; 2015), and Greene and Sullivan (2015). Dorsey (2016) criticizes these authors' arguments. 
(Seriously Mistaken) is a modest claim. It does not imply that everyone has good reason to hope that she is not seriously mistaken about her own life. It is compatible with the claim, which presumably many would endorse, that some people (e.g., people who believe themselves to have lived miserable lives) have no good reason to hope that they are not seriously mistaken about their own lives. (Seriously Mistaken) does not imply that being seriously mistaken about one's life is a great evil, or that it could never be rational to accept being thus seriously mistaken in exchange for sufficiently significant goods (as in a case in which one plugs oneself into the Matrix for 1,000 years of blissful Matrix-life). (Seriously Mistaken) merely implies that, typically, you have good reason to hope that you are not in gross error about who you are, about how your life has gone, and so on.

Now I shall make a claim that I hope will be uncontroversial: If I have actually had an extension into the past substantially longer than 30 years +9 months, then I am seriously mistaken about my own life. To illustrate, consider the fairly innocent-sounding supposition that I have actually had an extension into the past that is exactly 31 years in length. Entertaining this supposition causes me to confront a host of disturbing questions that collectively bring out the fact that if I have existed for exactly 31 years, then I at least have powerful reason to believe that I am seriously mistaken about my life. Why has everyone been telling me all my life that my birthday is April 13, 1988? Are my alleged parents my real parents? What if I really was born on April 13, 1988, but I have existed for exactly 31 years - then what? Did I exist for three months before I became a human conceptus? What on earth (or elsewhere) was I doing during those three months? Was I floating around as a disembodied soul? Where was I doing this? And so on. Such questions are easy to multiply. Such questions become easier to multiply, and more disturbing, when I entertain the supposition that I have actually had an extension into the past that is much more than 31 years in length-50 years, say. If I have existed for 50 years, then I am, or at least I have extremely powerful reason to believe myself to be, very seriously mistaken about my own life. Furthermore, there seems to be nothing special about me in this regard. In this regard, my situation seems to be extremely typical. Thus the following claim appears to be true:

(Past) Typically, a given person, A, is such that, for some amount of time, T: If A has actually had an extension into the past with length substantially greater than $\mathrm{T}$ (just a few years more than $\mathrm{T}$, say), then $\mathrm{A}$ is seriously mistaken about her own life.

These considerations bring out that (Seriously Mistaken) has the following normative upshot: Typically, a given person has good reason, for some amount of 
time, T, to hope that she has had an extension into the past with length not substantially greater than T. Importantly, this is so even if an extension into the past with length substantially greater than the amount of time in question would be better for one than an extension of one's life into the past with the length in question. A 1,000-year extension into the past might be better for me than an extension into the past of 30 years +9 months. But (Seriously Mistaken) implies that I have good reason to hope that I have not had a 1,000-year extension into the past and have instead had an extension into the past of (very close to) 30 years +9 months. $^{8}$

Now notice that no claim parallel to (Past) concerning extensions into the future appears to be true. The thought that I have actually received a 1,000-year extension into the past requires a radical revision of my self-conception. But the thought that I actually will receive a 1,000-year extension into the future requires nothing nearly so drastic. The second thought merely requires me to imagine that humans will perfect regenerative medicine, or will discover the Elixir of Life, or will do some other such thing within the next several decades. (This is a particular application of the general truth that the future is typically far more epistemically open than the past.) And, as before, there seems to be nothing special about $m e$ in this regard. Thus the following claim appears to be true:

(Future) It is not the case that, typically, a given person, A, is such that, for some amount of time, $\mathrm{T}$ : If $\mathrm{A}$ will actually receive an extension into the future with length substantially greater than $\mathrm{T}$, then $\mathrm{A}$ is seriously mistaken about her own life.

Now I can present the epistemic solution to the Hope Puzzle. Here it goes: (Seriously Mistaken) is true. Furthermore, (Past) is true. So, typically, a person has good reason, for some amount of time, $\mathrm{T}$, to hope that she has not actually had an extension into the past of length substantially greater than $\mathrm{T}$, even if an extension into the past of length substantially greater than $\mathrm{T}$ would be better for her than an extension into the past of length T. But if this is so, then, typically, a person has good reason to lack $\mathrm{H}$-. For if one has $\mathrm{H}-$, then, for every amount of time, $\mathrm{T}$, one prefers actually having received an extension into the past of length greater than $\mathrm{T}$ to actually having received an extension into the past of length $\mathrm{T}$, if the longer

8. Note, however, that (Seriously Mistaken) does not imply that a person typically has decisive overall reason to hope that she has had an extension into the past with length not substantially greater than the amount of time in question. For all (Seriously Mistaken) implies, everyone might have decisive overall reason to hope that she has existed since the beginning of time, or that time extends backward infinitely and that she has always existed. (Seriously Mistaken) merely implies that people typically have good reason to hope that they have had an extension into the past of not substantially more than such-and-such amount of time. 
extension would be better for one than the shorter one. Therefore, typically, a person has good reason to lack H-.${ }^{9}$ However, because (Future) is true, no piece of reasoning parallel to the one just articulated supports the conclusion that, typically, a person has good reason to lack $\mathrm{H}+$. So, although (Seriously Mistaken) typically recommends lacking $\mathrm{H}-$, it does not typically recommend lacking $\mathrm{H}+$. Furthermore, there is good reason to have $\mathrm{H}+$ : If one actually will receive a longer-and-better rather than a shorter-and-worse extension into the future, then one will have a better rather than a worse life (without being seriously mistaken about one's own life). So, having H+ typically has something rationally going for it that having H- does not. So goes the epistemic solution to the Hope Puzzle.

The epistemic solution is a vindicatory solution to the Hope Puzzle. But is it super-vindicatory? I think so. Typically, it does not occur to us to hope that our lives have gone in ways that are seriously inconsonant with our beliefs about them; and when we consider the possibility of having such hopes, we typically do not form them. Thus the reason to lack $\mathrm{H}$ - posited by the epistemic solution, namely the fact that if one has actually had a sufficiently long extension into the past, then one is seriously mistaken about one's own life, seems to be a reason for which people typically lack $\mathrm{H}-{ }^{10}$ Furthermore, presumably one reason for which people typically have $\mathrm{H}+$ is that if they actually will get a longer rather than a shorter extension into the future, then they will have a better rather than a worse life without being seriously mistaken about their own lives. And this is the reason to have $\mathrm{H}+$ posited by the epistemic solution. Thus the epistemic solution seems to be super-vindicatory.

9. Some might think that, typically, part of what it is to have $\mathrm{H}$ - is to hope that one is seriously mistaken about one's own life; and some might think that if this is so, then the claim that (Seriously Mistaken) is true amounts to little more than a flat insistence that people typically have good reason to lack H-. But it is not true that part of what it is to have $\mathrm{H}$ - is even typically to hope that one is seriously mistaken about one's own life. Rather, one's being seriously mistaken about one's own life is typically a consequence of one's having that for which one hopes in having H-. Furthermore, even if it were true that, typically, part of what it is to have $\mathrm{H}$ - is to hope that one is seriously mistaken about one's own life, (Seriously Mistaken) would seem to recommend the conclusion that one typically has good reason to lack H-. (It might be, however, that some people who have H- will find (Seriously Mistaken) implausible.)

10. Some might think that people typically lack H- simply because it is a hope concerning the past, and not even partly because, typically, one is massively mistaken about one's own life if one has had a sufficiently long extension into the past. But people often have hopes concerning the past. I have often, for example, hoped that some loved one of mine already got to the airport on time. However, I would be at least somewhat disinclined to hope that some loved one of mine already got to the airport on time if (for some bizarre reason) her having done so would imply that I am seriously mistaken about my own life, and I doubt that I am unusual in this respect. In general, it hardly seems unusual for a person to lack a hope at least partly because the satisfaction of this hope would imply that this person is massively mistaken about her own life. But if this is so, then I think it plausible that at least one reason for which people typically lack $\mathrm{H}$ - is that, typically, if one has had a sufficiently long extension into the past, then one is massively mistaken about one's own life. 


\section{The Wish Puzzle}

In this section, I shall describe a set of mental asymmetries different from the Hope Asymmetry, each of which can reasonably be characterized as a version of the Lucretian Asymmetry, and each of which I shall call a "version of the Wish Asymmetry." Versions of the Wish Asymmetry collectively give rise to a version of Lucretius' Puzzle that I shall call the "Wish Puzzle."

To begin with, note the non-counterfactual character of $\mathrm{H}+$ and of $\mathrm{H}-$. It is not the case that if a person has $\mathrm{H}+$, then she prefers that she would have received, rather than whatever extension into the future she actually will receive, some other, longer extension into the future instead (though having $\mathrm{H}+$ is compatible with having the preference just described). Rather, if a person has $\mathrm{H}+$, then she prefers actually receiving a longer extension into the future to actually receiving a shorter one. Similarly, it is not the case that if a person has $\mathrm{H}-$-, then she prefers (say) that she had received, rather than whatever extension into the past she actually has received, some other, longer extension into the past instead (though having $\mathrm{H}$ - is compatible with having this preference). Rather, if a person has $\mathrm{H}$-, then she prefers actually having received a longer extension into the past to actually having received a shorter one.

People can have attitudes similar to $\mathrm{H}+$ and to $\mathrm{H}-$ with a counterfactual character, too. Consider someone who prefers dying later than she actually will to dying when she actually will - whenever she actually will die. Such a person might have the following thought: "Some day-I don't know when-I shall die. But I'd rather not suffer my actual death, whenever it will occur. Instead, I'd prefer to suffer a different, later death." It seems strange to ascribe to this person a hope, for it seems strange to ascribe to anyone a hope that she will die later than she actually will. ${ }^{11}$ Rather, it seems more natural to ascribe to this person a wish, specifically a wish that she would die later than she actually will.

Wishes of the sort just imagined admit of infinitely many different versions. Someone could wish that he would die to years later than he actually will, or wish that he would die 207 years later than he actually will, or . . I shall call any wish of this sort a "version of W+." Furthermore, people can have wishes concerning their creations similar to versions of $\mathrm{W}+$. Someone could wish that he had come into existence 1 second earlier than he actually did, or wish that he had come into existence 8 million years earlier than he actually did, or ... I shall call any wish of this sort a "version of W-."

11. More exactly: It seems strange to ascribe to someone a de dicto hope that she will die later than she actually will. There is nothing strange about ascribing to someone a de re hope that she will die later than she actually will. 
I shall say that versions of $\mathrm{W}+$ and versions of $\mathrm{W}$ - can "correspond" to one another. What I mean by this is best brought out by examples. Consider a wishcall it " $\mathrm{W}+10$ " - that one would die 10 years later than one actually will; and consider a wish-call it "W-10" - that one had come into existence 10 years earlier than one actually did. W+10 and W-10 "correspond" to one another, as I use the term. By contrast, consider a wish - call it " $\mathrm{W}+20$ " - that one would die 20 years later than one actually will; and consider a wish-call it "W-8" - that one had come into existence eight years earlier than one actually did. W+2o and W-8 do not "correspond" to one another, as I use the term. I hope that these examples make my use of "correspond" intuitive.

A version of the Wish Asymmetry is the combination of possession of some version of $\mathrm{W}+$ and lack of a corresponding version of $\mathrm{W}-$. Because there are infinitely many mental asymmetries of this sort, there are infinitely many versions of the Wish Asymmetry.

Here is the Wish Puzzle:

Wish Puzzle. Does anything typically rationally recommend having a version of $\mathrm{W}+$ over having a corresponding version of $\mathrm{W}$-? If so, what? ${ }^{12}$

In Section 2, I suggested that people typically have the Hope Asymmetry. This is part of why I think it reasonable to characterize the Hope Asymmetry as "a version of the Lucretian Asymmetry." But some might wonder whether people typically have versions of the Wish Asymmetry. Clearly people typically lack versions of $\mathrm{W}$-. But do people typically have versions of $\mathrm{W}+$ ? A person who has a version of $\mathrm{W}+$ wishes that she were living, rather than her actual life, a life that would end later than her actual life. But it might seem strange to suppose that people typically have such wishes. Don't people typically just hope that they actually will go on living further and further into the future? Thus it might seem strange to regard versions of the Wish Asymmetry as versions of the Lucretian Asymmetry.

I think people sometimes have versions of $\mathrm{W}+$. Suppose your doctor tells you that you have one week to live, and that you consequently come to believe confidently that you will die within one week. Before you received this news, it might be that you hoped that you would go on living for at least several more years. But now it might be that you merely wish that you would die at least several years later than you actually will. And this wish is a version of $\mathrm{W}+$.

12. Harman (2011) takes the Wish Puzzle to be the central version of Lucretius' Puzzle. I shall argue later in this section that many other philosophers also understand Lucretius' Puzzle as a question at least very similar to the Wish Puzzle. 
Still, it might be thought that $\mathrm{H}+$ is more common than versions of $\mathrm{W}+$, and thus that the Hope Asymmetry is more common than versions of the Wish Asymmetry. But even if (as I suspect) the Hope Asymmetry is more common than versions of the Wish Asymmetry, I doubt that versions of the Wish Asymmetry are rare. So, although I believe that the Hope Asymmetry is worthier than any given version of the Wish Asymmetry of designation as "a version of the Lucretian Asymmetry," I doubt that versions of the Wish Asymmetry are unworthy of such designation. Versions of the Wish Asymmetry, or at any rate some of them, are mental asymmetries that people really do have, perhaps especially in circumstances in which they have come to regard themselves as having little or no control over what remains of their lives.

The Hope Puzzle and the Wish Puzzle are substantially different questions, not the same question formulated differently. Furthermore, what one says in response to one of these questions might have no bearing on the other. To show that this is so, I shall now identify a candidate for a vindicatory solution to the Hope Puzzle that cannot be adapted into a candidate for a vindicatory solution to the Wish Puzzle, as well as a candidate for a vindicatory solution to the Wish Puzzle that cannot be adapted into a candidate for a vindicatory solution to the Hope Puzzle.

First, consider the epistemic solution to the Hope Puzzle from Section 3. The epistemic solution cannot be adapted into a candidate for a vindicatory solution to the Wish Puzzle, for it is neither the case that I would have been seriously mistaken about my life if my death had been later than it actually will be nor the case that I would have been seriously mistaken about my life if my creation had been earlier than it actually was. (At any rate, I have no reason to believe that either of these counterfactual conditional claims is true.) So, a potential vindicatory solution to the Hope Puzzle might have no bearing on the Wish Puzzle. ${ }^{13}$

Second, consider the impossibility solution to Lucretius' Puzzle. Several philosophers have responded to some version or another of Lucretius' Puzzle by defending the following claim:

(Modal Asymmetry) Although no person could have come into existence before she actually did, every person could have gone out of existence after she actually did.

Any response to (some version of) Lucretius' Puzzle that appeals to (Modal Asymmetry) is a version of the impossibility solution. Different versions of the

13. I also believe that the future-bias-based solution to the Hope Puzzle that I mentioned in Section 3 cannot be adapted into a response to the Wish Puzzle. But this is a complicated issue that I cannot pursue here. 
impossibility solution differ from one another in (inter alia) how they go about defending (Modal Asymmetry). ${ }^{14}$

I shall not discuss the merits of the impossibility solution in this paper; other philosophers have raised objections to it that I find convincing. ${ }^{15}$ Instead, I shall defend the following claims:

(1) The impossibility solution can charitably be understood as aiming at showing that something rationally recommends having a version of $\mathrm{W}+$ over having a corresponding version of $\mathrm{W}-$.

(2) The impossibility solution cannot charitably be understood as aiming at showing that something rationally recommends having $\mathrm{H}+$ over having $\mathrm{H}-$.

Defense of (1). Suppose (Modal Asymmetry) is true. Then it is at least plausible that if I have a version of $\mathrm{W}+$, then things could have been as I wish they were in having this version of $\mathrm{W}+$. But if I have a corresponding version of $\mathrm{W}-$, then things could not have been as I wish they were in having this version of W-. So, (Modal Asymmetry) seems to support the conclusion that there is an interesting difference between a given version of $\mathrm{W}+$ and its corresponding version of $\mathrm{W}$-: Things could have been as one wishes they were in having a given version of $\mathrm{W}+$, but things could not have been as one wishes they were in having the corresponding version of $\mathrm{W}-$. But if this is so, then (1) is plausible.

Defense of (2). Suppose (Modal Asymmetry) is true. Nothing follows concerning how far in the future I might, for all I know, actually die or how far in the past I might, for all I know, actually have been created. For all (Modal Asymmetry) says, it might be that I actually shall die in 1 second and actually was created 14 billion years ago, or it might be that I actually shall die in 14 billion years and actually was created 1 second ago. But if I have $\mathrm{H}+$, then I have a preference for a death that is actually further rather than less far in the future; and if I have $\mathrm{H}$-, then I have a preference for a creation that is actually further rather than less far in the past. Thus (Modal Asymmetry) implies nothing either about the extent to which I might have $\mathrm{H}+$ satisfied or about the extent to which I might have $\mathrm{H}$ satisfied. But if this is so, then (2) is plausible.

(1) and (2) jointly imply that the impossibility solution is a candidate for a vindicatory solution to the Wish Puzzle that cannot be adapted into a candidate for a vindicatory solution to the Hope Puzzle. It follows that what one says about the Wish Puzzle might have no bearing on the Hope Puzzle.

14. Belshaw (2000), Kaufman (1995; 1996; 1999; 2000), and Nagel (1979) defend or express sympathy for versions of the impossibility solution.

15. Some objections to the impossibility solution can be found in Finocchiaro and Sullivan (2016) and Johansson (2013). 
Many philosophers appear to understand Lucretius' Puzzle as the Wish Puzzle, or least as some very similar question. Such philosophers presumably include proponents of the impossibility solution, for it is hard to imagine a question recognizable as a version of Lucretius' Puzzle very different from the Wish Puzzle to which the impossibility solution could at-all-plausibly be thought to be responsive. But many opponents of the impossibility solution appear to understand Lucretius' Puzzle as (something similar to) the Wish Puzzle, too. For although many philosophers reject the impossibility solution, I am aware of no philosopher who argues that the impossibility solution would not vindicate any version of the Lucretian Asymmetry even if every claim that is a part of the impossibility solution were true. But presumably at least some philosophers would argue as much if they did not understand at least one version of the Lucretian Asymmetry as (something similar to) the Wish Asymmetry. Thus even many opponents of the impossibility solution appear to understand at least one version of the Lucretian Asymmetry as (something similar to) the Wish Asymmetry and at least one version of Lucretius' Puzzle as (something similar to) the Wish Puzzle.

I shall consider whether the Wish Puzzle might have a super-vindicatory solution in Sections 5 and 6. Ultimately I shall argue that it does.

\section{The Attachment Solution}

In this section, I shall consider a candidate for a vindicatory solution to the Wish Puzzle defended by Elizabeth Harman (2011), namely the attachment solution. ${ }^{16}$

Harman says that, typically, if a person had come into existence substantially before she actually did, then her life would have gone very differently from her actual life (2011: 132). (Just try to imagine how your life would have gone had you come into existence even one month before you actually did.) ${ }^{17}$ Furthermore, Harman thinks that it follows that one who wishes that one had come into existence substantially before one actually did typically thereby wishes that one had lived a life that would have been very different from one's actual life.

To illustrate: Suppose the actual life of some person-call her "Sue" - begins at some time, $t$, goes some way or another, and then ends at some later time, $t^{*}$ :

16. McMahan (2006) and Meier (2019) also defend solutions to Lucretius' Puzzle at least very similar to the attachment solution.

17. Perhaps if you had come into existence 1 femtosecond before you actually did, then your life would have been very similar to your actual life. But it is clear that you typically have no reason to wish that you had come into existence 1 femtosecond before you actually did. 


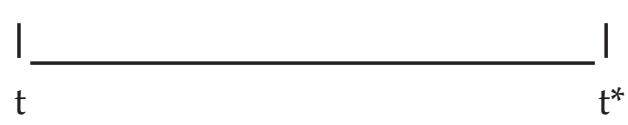

Figure 1. Actual Life of Sue

Suppose Sue wishes that she had come into existence 20 years before she actually did. Call this wish "W-20." Harman thinks that the life that Sue wishes that she had lived in having W-20 will (in the vast majority of cases) turn out to be very different from Sue's actual life. So, we might represent this life as follows:

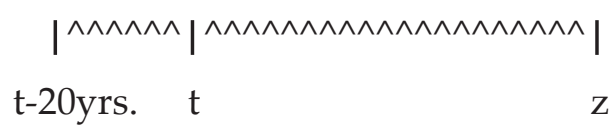

Figure 2. Earlier-Beginning Life of Sue

The carets in Figure 2 represent the fact that the earlier-beginning life of Sue is very different from the actual life of Sue. The letter ' $z$ ' refers to the last moment of the earlier-beginning life of Sue. (How z compares to $t$ will not matter for my purposes.)

Typically, Harman claims, one has good reason to lack a wish that one had lived a life that would have been very different from one's actual life. For, Harman claims, one typically has good reason to have "attachment to the actual," i.e., to have special attachments to the relationships, life-plans, and so forth that one's life actually contains, and to find counterfactual scenarios in which one would not have had these things, including scenarios in which one would have existed and would have fared better than one actually does, undesirable and even "horrific" (2011: 135-36). ${ }^{18}$ Because Harman thinks that one who has a version of $\mathrm{W}$ - typically thereby wishes that one had lived a life that would have been very different from one's actual life, Harman concludes that we typically have good reason to lack versions of $\mathrm{W}$-.

However, Harman claims, attachment to the actual does not recommend lacking a version of $\mathrm{W}+$. For, according to Harman, it is not the case that, typically, in having a version of $\mathrm{W}+$, one thereby wishes that one had lived a life that would have been very different from one's actual life. Thus it is not the case that, typically, in having a version of $\mathrm{W}+$, one thereby wishes that one had lived a life that would have differed from one's actual life with respect to one's actual attachments. Furthermore, Harman claims, if one has a version of W+,

18. Harman also discusses the rationality of attachment to the actual in her (2009). 
then the life that one thereby wishes one had lived is typically better than one's actual life. For, typically, longer lives are better than shorter ones, and (Harman thinks) the life that one wishes one had lived in having a version of $\mathrm{W}+$ is typically longer than one's actual life. So, Harman concludes, although attachment to the actual typically recommends against having a version of $\mathrm{W}-$-, attachment to the actual does not typically recommend against having a version of $\mathrm{W}+$; and there is typically good reason for a person to have a version of $\mathrm{W}+$. So, typically, having a version of $\mathrm{W}+$ has something rationally recommending it that having a version of W- does not. So goes Harman's attachment solution to the Wish Puzzle.

Before I can say what I think of the attachment solution, I need to make two points.

First, it seems not to be the case that, typically, if one had come into existence substantially before one actually did, then one would have had none of one's actual attachments. For example, my actual biological parents are among my actual attachments. Suppose, as many philosophers think, my actual biological parents are my biological parents in every world in which I exist. Then it seems plausible that if I had come into existence substantially before I actually did, then I would have had at least some of my actual attachments (among them my actual biological parents). And what goes for me goes for many other people.

It is thus important to note that the attachment solution does not rely on the claim that, typically, one would have had none of one's actual attachments if one had come into existence substantially before one did. Rather, it relies on the much more modest claim that, typically, one would have lacked some of one's actual attachments if one had come into existence substantially before one actually did. It what follows, I shall call some attachment that one has "fickle" just in case one would have lacked it if one had come into existence substantially before one actually did.

Second, the claim that attachment to the actual is reasonable can be understood in at least two ways. On the one hand, it can be understood as the claim that one can have good reason to lack a desire to exchange one's actual attachments for better things, because in that case one would lose (i.e., go, over time, from having to not having) one's actual attachments. I find this diachronic attachment view at least fairly plausible. I think it at least fairly plausible that Sue could have good reason to lack a desire (say) to exchange the car that she has had for the past five years for a better one, and that Sue could have good reason to lack this desire because Sue would lose one of her attachments if this exchange took place. ${ }^{19}$ On the other hand, the claim that attachment to the actual is reasonable

19. There might be limits to this. Perhaps Sue could have no good reason to want to keep her actual car if it is a terrible car, and perhaps Sue could have no good reason to prefer keeping her 
can be understood as the claim that one can have good reason to lack a wish that one had acquired things better than one's actual attachments instead of one's actual attachments, because in that case one would never have acquired one's actual attachments. I find this counterfactual attachment view, on which the attachment solution relies, less plausible than the diachronic attachment view. No doubt Sue might, in certain circumstances, have good reason to lack a wish that she had, instead of acquiring her actual car five years ago, acquired a better car. But I find it hard to believe that the bare fact that Sue would never have acquired her actual car had she acquired a better car instead gives Sue a reason to lack this wish. After all, if Sue had never acquired her actual car, then this car would not have been one of her attachments. In general, it seems less plausible that counterfactual attachment to the actual, i.e., the sort of attachment said to be reasonable by the counterfactual attachment view, is reasonable than that diachronic attachment to the actual, i.e., the sort of attachment said to be reasonable by the diachronic attachment view, is reasonable.

Now, some might allow that counterfactual attachment to the actual is unreasonable when applied to some things about which diachronic attachment to the actual is reasonable (e.g., one's car), but insist that counterfactual attachment to the actual is reasonable when applied to some other things (e.g., one's children). But I do not wish to insist that counterfactual attachment to the actual is unreasonable across the board. Rather, I wish merely to point out that the attachment solution succeeds only if counterfactual attachment to the actual is sometimes reasonable. I shall call some attachment that one has "heavy" just in case counterfactual attachment to the actual is reasonable as applied to it. (This terminological stipulation is neutral on whether or not any attachments are heavy.)

Now I can say what I think of the attachment solution. Suppose for argument's sake that some attachments are both fickle and heavy. ${ }^{20}$ Then I think that the attachment solution succeeds as applied to many people, specifically people with attachments that are both fickle and heavy. But the attachment solution does not apply to other people. But it seems that a person without attachments that are both fickle and heavy could have good reason to have a version of $\mathrm{W}+$ over its corresponding version of $\mathrm{W}$-. Consider, for example, a person who loves only his biological parents and has no projects that he cares deeply about. Such a person could, it seems, have no attachments that are both fickle and heavy; but I take it that such a person could have good reason to have a version of $\mathrm{W}+$ over its corresponding version of $\mathrm{W}$-. Thus I think that the attachment solution is

actual car to exchanging it for a vastly better car. But proponents of the diachronic attachment view need not deny these things.

20. Adequately pursuing the question whether this supposition is correct (which is almost entirely a matter of pursuing the question whether there are heavy attachments) would require a separate paper. 
importantly incomplete, even if successful so far as it goes. We ought to look for a more complete solution to the Wish Puzzle, which would apply even to people without attachments that are both fickle and heavy.

\section{The Different Lengths Solution}

Harman suggests another candidate for a vindicatory solution to the Wish Puzzle, which is independent of her attachment solution. As I mentioned in Section 5, Harman endorses the following claim:

(W+ Longer) Typically, if a given person, $\mathrm{A}$, has a version of $\mathrm{W}+$, then: In having this version of $\mathrm{W}+, \mathrm{A}$ wishes that $\mathrm{A}$ were living a life longer than A's actual life.

However, Harman (2011: 132-33) also defends the following claim:

(W- Not Longer) It is not the case that, typically, if a given person, A, has a version of $W_{-}$, then: In having this version of $W_{-}, A$ wishes that $A$ were living a life longer than A's actual life.

But if (W+ Longer) and (W- Not Longer) are both true, then it seems very plausible that having a version of $\mathrm{W}+$ has something rationally going for it over having a corresponding version of $\mathrm{W}$-. So, if (W+ Longer) and (W- Not Longer) are both true, then the Wish Puzzle seems to have a vindicatory solution. We can call this candidate for a vindicatory solution to the Wish Puzzle the different lengths solution. (Note that the different lengths solution, if successful, applies even to people who do not have attachments that are both fickle and heavy.)

Call the conjunction of (W+ Longer) and (W- Not Longer) "(Length Asymmetry)." Why think (Length Asymmetry) is true? Harman appears to take the claims that she defends in the following passage to support (Length Asymmetry):

Consideration of the counterfactual possibility in which a person dies later [than she actually does] just is consideration of a counterfactual possibility in which she is nevertheless created at the same time [as she actually is] holding fixed the time of her creation requires no further stipulation: it follows straightforwardly from imagining the closest possibility in which she dies later [than she actually does]. But consideration of the counterfactual possibility in which a person is created earlier [than she actually is] is not consideration of a counterfactual possibility in which she nevertheless dies at the time of her actual death. [...] [It] would be very coincidental if a 
person was such that, had she been created earlier [than she actually was], she would nevertheless have died at the same time [as she actually does]. (Such a case is possible but unusual.) (2011: 133-34)

In this passage, Harman appears to endorse the following two claims, and to think that they jointly support (Length Asymmetry):

(Later) Typically, the closest possible world in which a given person, A, dies some amount of time, T, later than A actually does is one in which A's life begins when A's actual life begins and ends T later than A's actual life ends, and thus is longer than A's actual life.

(Earlier) It is not the case that, typically, the closest possible world in which a given person, $\mathrm{A}$, comes into existence some amount of time, $\mathrm{T}$, earlier than A actually does is one in which A's life begins T earlier than A's actual life begins and ends when A's actual life ends, and thus is longer than A's actual life.

But it is difficult to see how one might take (Later) and (Earlier) to support (Length Asymmetry) unless one also endorsed a principle at least very similar to the following one:

(Wish-World Principle) If a given person, A, has a wish that it were the case that $\mathrm{p}$, then: In having this wish, A wishes that the closest possible world where $\mathrm{p}$ were actual. ${ }^{21}$

(Later) and (Wish-World Principle) jointly support (W+ Longer). And it might be thought that (Earlier) and (Wish-World Principle) jointly support (W- Not Longer). ${ }^{22}$ So, it might be thought, (Later), (Earlier), and (Wish-World Principle)

21. What is it to wish that a given non-actual world were actual? I am not sure. One possibility is that to have such a wish is to prefer the non-actual world in question to the actual world. At any rate, I take it to be clear that Harman's argument requires a claim at least very similar to (Wish-World Principle).

22. Actually there is a complication here. (Earlier) and (Wish-World Principle) jointly support the following conclusion:

${ }^{*}$ It is not the case that, typically, if a given person, $\mathrm{A}$, has a version of $\mathrm{W}-$, then: In having this version of $\mathrm{W}-$, A wishes that A were living a life that begins earlier than A's actual life begins and ends when A's actual life ends, and thus is longer than A's actual life.

But $\left({ }^{*}\right)$ is a weaker claim than (W- Not Longer). $\left({ }^{*}\right)$ is compatible with the following claim:

(W- Longer) Typically, if a given person, $\mathrm{A}$, has a version of $\mathrm{W}-$-, then: In having this version of $\mathrm{W}-$-, A wishes that A were living a life longer than $\mathrm{A}^{\prime}$ 's actual life. 
jointly support (Length Asymmetry). Thus I am inclined to interpret Harman as arguing from the conjunction of (Later), (Earlier), and (Wish-World Principle) to the conclusion that (Length Asymmetry) is true.

What ought we think of this argument for (Length Asymmetry)? I think that we ought to reject it, because I think that we ought to reject (Wish-World Principle).

Suppose I wish that I would die 1 trillion years later than I actually will. Call this wish of mine "W+1T." Perhaps the closest possible world in which I die 1 trillion years later than I actually do is one in which I come into existence when I actually do, live for 1 trillion more years than I actually do, and then die. But perhaps this is not the case. Perhaps - to pick just one alternative epistemic possibility among infinitely many - the closest possible world in which I die 1 trillion years later than I actually do is one in which I come into existence about 1 trillion years later than I actually do, live for about as long as I actually do, and then die. ${ }^{23}$ What matters for my purposes is that I have no clue which, if either, of these two alternatives is the case. Which, if either, of these alternatives is the case depends on abstruse facts about the composition of modal space far beyond my, or anyone's, ken. (Indeed, whether there is a closest world of the relevant sort is beyond anyone's ken.) However, it seems implausible that the content of $W+1 T$ might be hostage to such abstruse facts. Typically, anyway, if I have $\mathrm{W}+1 \mathrm{~T}$, then I thereby wish that my life would go on for a trillion more years than it actually will; and-this is the crucial point-this is so regardless of how modal space happens to be composed. But (Wish-World Principle) implies otherwise. (WishWorld Principle) implies that if, in having W+1T, I thereby wish that my life would go on for 1 trillion more years than it actually will, then this is because of facts about the composition of modal space. And this seems implausible. So, I think that we ought to reject (Wish-World Principle), for it implies that the contents of wishes are sensitive to facts about the composition of modal space to which they seem not to be sensitive. ${ }^{24}$

And (Earlier) and (Wish-World Principle) are compatible with (W- Longer), too. So, the claims that Harman appears to adduce in favor of (W- Not Longer) do not actually jointly entail (W- Not Longer).

Having raised this difficulty, I shall set it aside. For I think that there is reason to believe that (Earlier) and (Wish-World Principle) jointly support (W- Not Longer) even though they do not jointly entail (W- Not Longer), but this is a complicated matter that I do not want to pursue in this paper.

23. Some views about the metaphysics of modality will rule out the possibility that some such world is the closest world in which I die 1 trillion years later than I actually do. But such views are not obviously true, and at any rate it would seem to be a deficiency of Harman's argument for (Length Asymmetry) that it relied on some such view.

24. Note that I am not saying that the truth or falsity of a given counterfactual conditional proposition is insensitive to facts about the composition of modal space. I take no stand on why 
Now, (Length Asymmetry) might be true even though Harman's defense of it is unsuccessful. And in fact, I think that two considerations jointly support the conclusion that (Length Asymmetry) is true.

Consideration 1. It seems that versions of $\mathrm{W}+$ typically have, so to speak, time-of-creation-preservation clauses built into their contents. Return to $\mathrm{W}+1 \mathrm{~T}$, for example. It seems clear that part of what I wish were the case, in having $\mathrm{W}+1 \mathrm{~T}$, is that my time of creation be the same as my actual time of creation (so that I would have ended up having a life 1 trillion years longer than my actual life). And presumably this typically also holds for less extreme versions of $\mathrm{W}+$, such a wish that one would die one month later than one actually will. That is, presumably, less extreme versions of $\mathrm{W}+$ also typically have time-of-creation-preservation clauses built into their contents. But if versions of $\mathrm{W}+$ typically have time-of-creation-preservation clauses built into their contents, then it appears that (W+ Longer) is true. ${ }^{25}$

Consideration 2. It seems plausible that versions of W- typically do not have, so to speak, time-of-death-preservation clauses built into their contents. That is, it seems plausible that, typically, if one has a version of $\mathrm{W}-$, then it is not the case that part of what one wishes were the case is that the time of one's death be the actual time of one's death. But if this is so, then it appears that (W- Not Longer) is true.

Thus Consideration 1 and Consideration 2 seem jointly to provide support for (Length Asymmetry). So, it seems that the different lengths solution is a successful vindicatory solution to the Wish Puzzle after all. Furthermore, the different lengths solution seems to qualify as super-vindicatory. For it seems plausible that, typically, a reason for which people who have versions of $\mathrm{W}+$ do so is the fact that, in having these wishes, they typically thereby wish that their lives had been longer than their actual lives and, typically, a reason for which people who lack versions of $\mathrm{W}$ - do so is the fact that it is not the case that, in having such a wish, they typically would thereby wish that their lives had been longer than their actual lives. Thus I think that the different lengths solution is a super-vindicatory solution to the Wish Puzzle.

counterfactual conditional propositions have the truth-values that they have. My present point has only to do with the contents of wishes.

25. Someone of course could wish (say) that she were living whatever life she lives in the closest possible world in which she dies one month later than she actually will. Thus it is possible to have a version of $\mathrm{W}+$ without a time-of-creation-preservation-clause built into its content. But such wishes are plainly massively atypical. 


\section{The Wish Puzzle*}

I just argued, by appeal to Consideration 1 and Consideration 2, that the different-lengths solution is a super-vindicatory solution to the Wish Puzzle. I shall now argue that Consideration 1 and Consideration 2 help to bring out a version of Lucretius' Puzzle slightly different from the Wish Puzzle to which the different lengths solution is not responsive.

Consideration 1 implies that versions of $\mathrm{W}+$ typically have time-of-creationpreservation clauses built into their contents. Furthermore, although (as Consideration 2 implies) versions of $\mathrm{W}$ - typically do not have time-of-death-preservation clauses built into their contents, versions of $\mathrm{W}$ - with such clauses built into their contents are clearly possible. So, we can just ask directly whether having a version of $\mathrm{W}+$ with a time-of-creation-preservation clause built into it has anything rationally going for it over having a corresponding version of W-with a time-of-death-preservation-clause built into it. And this question cannot be satisfactorily answered merely by insisting that people typically do not have versions of $\mathrm{W}$ - with time-ofdeath-preservation-clauses built into them.

Call any wish that one would die later than one actually will with the time of one's creation held constant a "version of $\mathrm{W}^{*}+$. " Call any wish that one had been created earlier than one actually was with the time of one's death held constant a "version of $\mathrm{W}^{*}$-." Every version of $\mathrm{W}^{*}+$ is a version of $\mathrm{W}+$, but the reverse does not hold; and every version of $\mathrm{W}^{*}$ - is a version of $\mathrm{W}_{-}$, but the reverse does not hold.

Say that a given version of $\mathrm{W}^{*}+$ and a given version of $\mathrm{W}^{*}$ - "correspond" to one another just in case they relate to one another as a version of $\mathrm{W}+$ and a version of $\mathrm{W}$ - that correspond to one another relate to one another. For example, consider a wish-call it " $\mathrm{W}^{*}+10^{\prime}$ " that one would die 10 years later than one actually will with the time of one's creation held constant. And consider a wish - call it " $\mathrm{W}^{*}-1 \mathrm{O}^{\prime}$ " - that one had come into existence 10 years before one actually did with the time of one's death held constant. $W^{*}+10$ and $W^{*}-10$ "correspond" to one another, as I use the term.

A version of the "Wish Asymmetry"," as we might call it, is the combination of possession of a version of $\mathrm{W}^{*}+$ and lack of a corresponding version of $\mathrm{W}^{*}$-. Just as there are infinitely many versions of the Wish Asymmetry, there are infinitely many versions of the Wish Asymmetry*. The infinitely many versions of the Wish Asymmetry* collectively give rise to the following version of Lucretius' Puzzle:

Wish Puzzle*. Does anything typically rationally recommend having a version of $\mathrm{W}^{*}+$ over having a corresponding version of $\mathrm{W}^{*}$-? If so, what? 
To illustrate: Return to $\mathrm{W}^{*}+10$ and $\mathrm{W}^{*}-10$. The Wish Puzzle* asks (inter alia) the following question: Does anything typically rationally recommend having $\mathrm{W}^{*}+10$ over having $\mathrm{W}^{*}-10$; and if so, what?

Although the different lengths solution is a successful super-vindicatory solution to the Wish Puzzle (or so I have argued), the different lengths solution is not a successful vindicatory (much less super-vindicatory) solution to the Wish Puzzle*. This can be seen by attending to the fact that the life that one wishes one were living in having $\mathrm{W}^{*}+10$ if one has this wish is no longer than the life that one wishes one were living in having $\mathrm{W}^{*}-10$ if one has this wish.

Is the Wish Puzzle* a less interesting question than the Wish Puzzle? The Wish Puzzle* is less interesting than the Wish Puzzle only to the extent that versions of $\mathrm{W}^{*}+$ specifically are less typical than versions of $\mathrm{W}+$ generally. But I have argued that people very rarely have versions of $\mathrm{W}+$ that are not also versions of $\mathrm{W}^{*}$. Thus I take the Wish Puzzle ${ }^{*}$ to be at most very slightly less interesting than the Wish Puzzle. ${ }^{26}$

I shall consider whether the Wish Puzzle* might have a super-vindicatory solution in Sections 8 and 9. Ultimately I shall conclude that it probably does not even have a vindicatory solution.

\section{The Further-Ahead Solution}

In this section, I shall consider a candidate for a vindicatory solution to the Wish Puzzle* that might have occurred to some readers, which I shall call the further-ahead solution.

Recall $\mathrm{W}^{*}+10$ and $\mathrm{W}^{*}-10$, which were introduced in Section 7. Call the life that I wish I were living if I have $\mathrm{W}^{*}+10$ " $\mathrm{L}\left(\mathrm{W}^{*}+10\right)$," and call the life that I wish I were living if I have $\mathrm{W}^{*}-10$ " $\mathrm{L}\left(\mathrm{W}^{*}-10\right)$." Applied, in my own case, to $\mathrm{W}^{*}+10$ and to $W^{*}-10$, the further-ahead solution goes as follows: (A) If I were living $\mathrm{L}\left(\mathrm{W}^{*}+10\right)$, then I would have more life ahead of me than I would have ahead of me if I were living $\mathrm{L}\left(\mathrm{W}^{*}-10\right)$. (B) One has good reason, ceteris paribus, to prefer living a life in which there would be more life ahead of one to living a different life in which there would be less life ahead of one. But if (A) and (B) are both true, then there is a consideration that rationally recommends my having $W^{*}+10$ over my having $\mathrm{W}^{*}-10$ : In having $\mathrm{W}^{*}+10$, I wish that I were living a life in which there would be more life ahead of me than there would be ahead of me in the life that

26. On this point, I disagree with Harman (2011: 133). Harman entertains a version of Lucretius' Puzzle very similar to the Wish Puzzle*, but she takes it to be uninteresting because she (unlike me) takes versions of $W^{*}+$ specifically to be much less common than versions of $\mathrm{W}+$ generally. 
I wish I were living in having $\mathrm{W}^{*}$-10. And the point generalizes to all people, and to all versions of $\mathrm{W}^{*}+$ and their corresponding versions of $\mathrm{W}^{*}$-. So goes the further-ahead solution.

The further-ahead solution includes a premise to the effect that people have good reason to have a kind of future-bias, namely (B). Thus opponents of futurebias will presumably reject the further-ahead solution. But I shall not object to the further-ahead solution in this way. Instead, I shall argue that (A) and (B), if they are interpreted in the manner required by the further-ahead solution, jointly yield an absurd consequence.

Here some figures will help. Figure 3 represents my actual life, Figure 4 represents $\mathrm{L}\left(\mathrm{W}^{*}+10\right)$, and Figure 5 represents $\mathrm{L}\left(\mathrm{W}^{*}-10\right)$. The ' $\mathrm{x}^{\prime}$ ' in Figure 3 refers to the time that is the present in the actual world, which is also, let us assume, $t+30$ years:

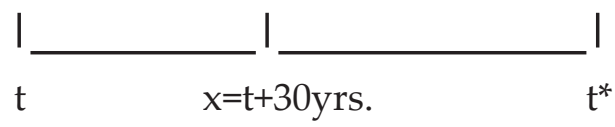

Figure 3. Actual Life

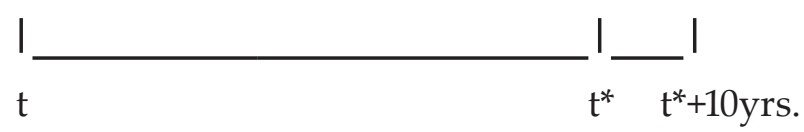

Figure 4. $L\left(W^{*}+10\right)$

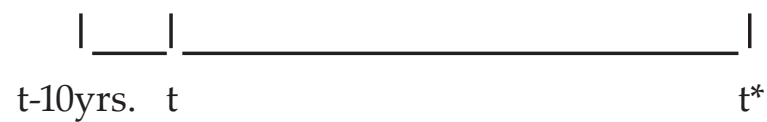

Figure 5. $L\left(W^{*}-10\right)$

It will not matter for my purposes how qualitatively similar to one another these lives are.

Suppose (A) is true. Why is (A) true? Presumably the defender of (A) must answer this question in something like the following way: If I were living $\mathrm{L}\left(\mathrm{W}^{*}+10\right)$, then it would now be $\mathrm{t}+30$ years, as it is in the actual world; and, similarly, if I were living $\mathrm{L}\left(\mathrm{W}^{*}-10\right)$, then it would now be $\mathrm{t}+30$ years, as it is in the actual world. But there is more temporal distance separating $\mathrm{t}+30$ years from $t^{*}+10$ years than separating $t+30$ years from $t^{*}$. So, there would now be more life ahead of me if I were living $\mathrm{L}\left(\mathrm{W}^{*}+10\right)$ than if I were living $\mathrm{L}\left(\mathrm{W}^{*}-10\right)$. This, it seems, is why (A) is true, if (A) is true. 
Hold that thought. Now consider a third possible wish, which I shall call "WWW." This is a wish that one were living a life that would have started 1o years later than one's actual life and ended 20 years later than one's actual life. Call the life that I wish I were living if I have WWW "L(WWW)." To illustrate:

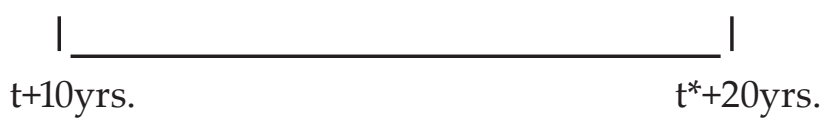

Figure 6. $L(W W W)$

$\mathrm{L}(\mathrm{WWW})$ is the same length as $\mathrm{L}\left(\mathrm{W}^{*}+10\right)$, but $\mathrm{L}(\mathrm{WWW})$ ends 10 years later than $\mathrm{L}\left(\mathrm{W}^{*}+10\right)$ does.

By the lights of the current proposal, it seems inescapable that if I were living $\mathrm{L}(\mathrm{WWW})$, then it would now be $\mathrm{t}+30$ years, as it is in the actual world. Therefore, there would now be more life ahead of me if I were living L(WWW) than if I were living $\mathrm{L}\left(\mathrm{W}^{*}+10\right)$. So, if $(\mathrm{B})$-interpreted in the manner required by the further-ahead solution - is true, then it seems inescapable that, just as there is a consideration recommending my having $\mathrm{W}^{*}+10$ over my having $\mathrm{W}^{*}-10$, there is a consideration recommending my having WWW over my having $W^{*}+10$. But this is absurd. Nothing recommends my having WWW over my having $\mathrm{W}^{*}+10$, ceteris paribus anyway. So, something has gone wrong here. The further-ahead solution is unsuccessful.

I shall take no stand on what has gone wrong here, but I shall briefly flag two possibilities.

One possibility is that (A) is false. (A) presupposes that there is a fact of the matter concerning what time the present would have been if I had been living $\mathrm{L}\left(\mathrm{W}^{*}+10\right)$, as well as a fact of the matter concerning what time the present would have been if I had been living $\mathrm{L}\left(\mathrm{W}^{*}-10\right)$. But perhaps there are no facts of the matter concerning these topics.

Another (compatible) possibility is that (B) is false. I am attracted to this view. But here I want to be careful: What I am attracted to is the view that (B) is false if $(B)$ is interpreted as applying not only to hopeful preferences but also to wishful preferences, as it must be interpreted in order for it to yield, along with (A), the conclusion that there is a consideration recommending having $\mathrm{W}^{*}+10$ over having $W^{*}-10$. However, if $(B)$ is interpreted as applying only to hopeful preferences, then I think that (B) is much more plausible. But, so interpreted, it cannot yield, along with (A), the conclusion that something rationally recommends having $\mathrm{W}^{*}+10$ over having $\mathrm{W}^{*}$-10.

To see what I mean by this, and why I think this, consider the following case, which is an expanded version of a case introduced in Section 2: 
Younger or Older. You wake up in the hospital with total amnesia. The nurse tells you that you either are 40 years old and have 40 more years to live or are 50 years old and have 30 more years to live. The nurse leaves the room to find out which person you are. While the nurse is away, you hope that you are 40 years old.

Suppose for argument's sake-pace opponents of future-bias - that you have good reason to hope that you are 40 while the nurse is away. Then it appears that (B) is true if it is interpreted as applying only to hopeful preferences, such as the one that you have while the nurse is away. Thus the view to which I am attracted is not that (B) is utterly false. Rather, the view to which I am attracted is that (B), interpreted as applying both to hopeful preferences and to wishful preferences, is false.

More could be said about all of this. But in light of the problem that I have raised for the further-ahead solution to the Wish Puzzle*, I think that we ought to reject it.

\section{The Easiness Solution}

Sections 5-8 collectively ought, I think, to cast doubt on the thought that the Wish Puzzle* admits of a successful vindicatory (much less super-vindicatory) solution. Return to $\mathrm{W}^{*}+10$ and $\mathrm{W}^{*}$-10. $\mathrm{L}\left(\mathrm{W}^{*}+10\right)$, i.e., the life that one wishes one were living in having $\mathrm{W}^{*}+10$, might contain some of one's actual attachments not contained in $\mathrm{L}\left(\mathrm{W}^{*}-10\right)$, i.e., the life that one wishes one were living in having $\mathrm{W}^{*}-10$; but this fact recommends having $\mathrm{W}^{*}+10$ over having $\mathrm{W}^{*}$-10 only if some of these attachments are both fickle and heavy. Neither $L\left(W^{*}+10\right)$ nor $L\left(W^{*}-10\right)$ is longer than the other, so neither is better for one than the other, ceteris paribus. And it does not seem to be the case both that there would be more life ahead of one if one were living $\mathrm{L}\left(\mathrm{W}^{*}+10\right)$ than if one were living $\mathrm{L}\left(\mathrm{W}^{*}-10\right)$ and that this fact rationally recommends having $W^{*}+10$ over having $W^{*}-10$. What, then, could rationally recommend having $\mathrm{W}^{*}+10$ over having $\mathrm{W}^{*}-10$ (aside from a difference with respect to fickle-and-heavy attachments)?

Perhaps some might say that $\mathrm{L}\left(\mathrm{W}^{*}+10\right)$ is easier to imagine than $\mathrm{L}\left(\mathrm{W}^{*}-10\right)$, and that this fact rationally recommends having $W^{*}+10$ over having $W^{*}-10$. In order to imagine $\mathrm{L}\left(\mathrm{W}^{*}+10\right)$, one must imagine one's own life (or one's own life up to the present) and then imagine "gluing" some extra life to the end (or to one's own life as it has gone up to the present) such that the resultant life ends 10 years later than one's actual life does. Typically, this is a fairly easy mental performance. But in order to imagine $\mathrm{L}\left(\mathrm{W}^{*}-10\right)$, one must imagine gluing some additional life to the beginning of one's life, or one must imagine "sliding back" one's own life in time and then gluing some additional life to the end, or one must imagine some dramatically qualitatively different life that starts before one's actual life starts and 
ends when one's actual life ends, so that the resultant life starts 10 years before one's actual life starts but ends when one's actual life ends. These mental performances all typically require a fair amount of effort. So, perhaps some might say that although nothing typically recommends $L\left(W^{*}+10\right)$ over $L\left(W^{*}-10\right)$, something typically recommends having $W^{*}+10$ over having $W^{*}-10$ : Typically, having $W^{*}+10$ requires less imaginative effort than having $W^{*}-10$. And presumably the point applies generally to versions of $\mathrm{W}^{*}+$ and to their corresponding versions of $\mathrm{W}^{*}$.

This easiness solution to the Wish Puzzle* strikes me as the best candidate for a super-vindicatory solution to the Wish Puzzle*. But I doubt that the easiness solution really counts as a vindicatory solution to the Wish Puzzle*, for I doubt that the fact that having a version of $\mathrm{W}^{*}+$ is easier than having a corresponding version of $\mathrm{W}^{*}$ - rationally recommends having a version of $\mathrm{W}^{*}+$ over having a corresponding version of $\mathrm{W}^{*}$-. In general, I doubt that the difficulty of having a given attitude is a factor that can make a difference to the rationality of having this attitude. This thought seems implausible when applied to doxastic attitudes, for example. The fact that having a belief that it is raining would be difficult for you (perhaps because you have a hard time imagining rainfall but would need to form an at least sketchy imaginative representation of rainfall in order to have this belief) does not seem to count rationally against having this belief. It is perhaps more plausible that the difficulty of having a given desire is a factor that contributes to the rationality of having this desire; and wishes are more like desires than like beliefs. Still, the easiness solution makes me nervous.

That being said, the easiness solution can be adapted into a plausible (at least partial) explanation of the fact that versions of $\mathrm{W}^{*}+$ are more common than corresponding versions of $\mathrm{W}^{*}$-: Versions of $\mathrm{W}^{*}+$ are more common than corresponding versions of $\mathrm{W}^{*}$ - because, typically, having a given version of $\mathrm{W}^{*}+$ requires less effort than does having the corresponding version of $W^{*}$-. So, some might content themselves with the following "satisfying non-vindicatory solution" to the Wish Puzzle*, so to speak: Nothing rationally recommends having a version of $\mathrm{W}^{*}+$ over having a corresponding version of $\mathrm{W}^{*}$-, but there is no mystery about why versions of $\mathrm{W}^{*}+$ are more common than corresponding versions of $\mathrm{W}^{*}$-. (One could give a parallel "satisfying non-vindicatory solution" to the Wish Puzzle, too.) This conclusion-according to which the Wish Puzzle* does not have a vindicatory solution but does have a satisfying non-vindicatory solution - is the one to which I am most attracted.

\section{Conclusion}

In this paper, Ihave argued that the epistemic solution is a super-vindicatory solution to the Hope Puzzle; that the different lengths solution is a super-vindicatory 
solution to the Wish Puzzle; and that the Wish Puzzle* probably lacks a vindicatory (or super-vindicatory) solution.

There are versions of Lucretius' Puzzle other than the ones considered in this paper. My discussion has not been comprehensive. However, I suspect that my discussion has been close to comprehensive. For I doubt that there is any mental asymmetry, MA, that meets the following conditions: (a) MA is very different from the Hope Asymmetry; (b) MA is very different from any version of the Wish Asymmetry; and (c) MA can reasonably be characterized as "the combination of a preference that one's death be later rather than earlier and the lack of a preference that one's creation be earlier rather than later." But presumably a mental asymmetry would have to meet conditions (a)-(c) in order for it to give rise to a version of Lucretius' Puzzle to which what I have said in this paper is inapplicable. This is why I suspect that my discussion has been close to comprehensive. I suspect that what I have said in this paper could be brought to bear on any question worth calling "a version of Lucretius' Puzzle."

\section{Acknowledgments}

Thanks to Selim Berker; Javier Caride; Frances Kamm; Thomas Scanlon; Heather Spradley; audiences at Kenyon, Princeton, Syracuse, and an APA; my fellow participants in Harvard's Workshop in Moral and Political Philosophy; and two anonymous reviewers for Ergo.

\section{References}

Belshaw, Christopher (2000). Death, Pain, and Time. Philosophical Studies, 97, 317-41.

Brink, David. (2011). Prospects for Temporal Neutrality. In Craig Callendar (Ed.), The Oxford Handbook of the Philosophy of Time (353-81). Oxford University Press.

Brueckner, Anthony and John Martin Fischer (1986). Why Is Death Bad? Philosophical Studies, 50(2), 213-21.

Brueckner, Anthony and John Martin Fischer (1993). The Asymmetry of Early Death and Late Birth. Philosophical Studies, 71(3), 327-31.

Brueckner, Anthony and John Martin Fischer (2013). The Evil of Death and the Lucretian Asymmetry: A Reply to Feldman. Philosophical Studies, 163(3), 783-89.

Deng, Natalja (2015). How A-Theoretic Deprivationists Should Respond to Lucretius. Journal of the American Philosophical Association, 1(3), 417-32.

Dorsey, Dale (2016). Future-Bias: A (Qualified) Defense. Pacific Philosophical Quarterly, 98(S1), 351-73.

Dougherty, Tom (2011). On Whether to Prefer Pain to Pass. Ethics, 121(3), 521-37.

Dougherty, Tom (2015). Future-Bias and Practical Reason. Philosophers' Imprint, 15(30), $1-16$. 
Feldman, Fred (1991). Some Puzzles about the Evil of Death. Philosophical Review, 100(2), 205-27.

Finocchiaro, Peter and Meghan Sullivan (2016). Yet Another "Epicurean" Argument. Philosophical Perspectives, 30(1), 135-59.

Greene, Preston and Meghan Sullivan (2015). Against Time Bias. Ethics, 125(4), 947-70.

Harman, Elizabeth (2009). "I'll Be Glad I Did It" Reasoning and the Significance of Future Desires. Philosophical Perspectives, 23(1), 177-99.

Harman, Elizabeth (2011). Fischer and Lamenting Nonexistence. Social Theory and Practice, 37(1), 129-42.

Johansson, Jens (2013). Past and Future Nonexistence. Journal of Ethics, 17, 51-64.

Kamm, Frances (1993). Morality, Mortality Volume I: Death and Whom to Save from It. University Press.

Kaufman, Frederik (1995). An Answer to Lucretius' Symmetry Argument against the Fear of Death. Journal of Value Inquiry, 29, 57-64.

Kaufman, Frederik (1996). Death and Deprivation; Or, Why Lucretius' Symmetry Argument Fails. Australasian Journal of Philosophy, 74(2), 305-12.

Kaufman, Frederik (1999). Pre-Vital and Post-Mortem Non-Existence. American Philosophical Quarterly, 36(1), 1-19.

Kaufman, Frederik (2000). Thick and Thin Selves: Reply to Fischer and Speak. Midwest Studies in Philosophy, 24, 94-97.

McMahan, Jeff (2006). The Lucretian Argument. In Kris McDaniel, Jason R. Raibley, Richard Feldman, and Michael J. Zimmerman (Eds.), The Good, the Right, Life and Death: Essays in Honor of Fred Feldman (213-26). Ashgate Publishing.

Meier, Lukas (2019). What Matters in the Mirror of Time: Why Lucretius' Symmetry Argument Fails. Australasian Journal of Philosophy, 97(4), 651-60.

Nagel, Thomas (1979). Death. In Mortal Questions (1-10). Cambridge University Press.

Nagel, Thomas (1986). The View from Nowhere. Oxford University Press.

Parfit, Derek (1984). Reasons and Persons. University Press.

Rosenbaum, Stephen (1989). The Symmetry Argument: Lucretius Against the Fear of Death. Philosophy and Phenomenological Reseearch, 50(2), 353-73.

Sorensen, Roy (2013). The Symmetry Problem. In Ben Bradley, Fred Feldman, and Jens Johansson (Eds.), The Oxford Handbook of Philosophy of Death (234-54). Oxford University Press.

Timmerman, Travis. (2018). Avoiding the Asymmetry Problem. Ratio, 31(1), 88-102. 